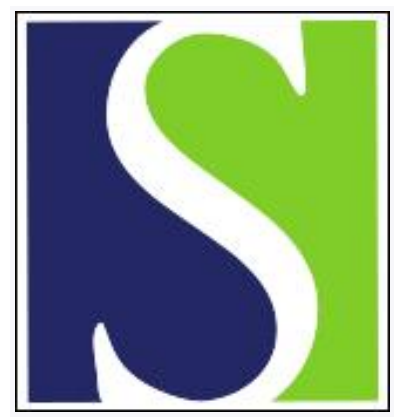

Scand J Work Environ Health Online-first -article

https://doi.org/10.5271/sjweh.2917

Published online: 07 Apr 2010

The work ability index and single-item question: associations with sick leave, symptoms, and health - a prospective study of women on long-term sick leave

by Ahlstrom L, Grimby-Ekman A, Hagberg M, Dellve L

Affiliation: Occupational and Environmental Medicine, Sahlgrenska Academy, University of Gothenburg, S-405 30 Gothenburg, Sweden. linda.ahlstrom@amm.gu.se

Refers to the following texts of the Journal: 2009;35(1):37-47 2006;32(1):75-84 2008;34(4):239-249 2009;35(1):1-5 1997;23 suppl $1: 66-71 \quad 2002 ; 28(3): 184-190 \quad 2003 ; 29(6): 444-451$

2005;31(6):438-449 2009;35(5):325-333

The following articles refer to this text: 2010;36(6):515-516;

2011;37(6):455-463; 2011;37(6):451-453; 2013;39(1):57-65;

2012;38(6):600-603; 2013;39(5):456-467; 2014;40(4):428-431;

2014;40(5):473-482; 2015;41(1):36-42; 2015;41(4):338-346;

2016;42(6):490-499; 2017;43(4):337-349; 2020;46(2):168-176

Key terms: cohort study; female; health; long-term sick leave; longitudinal data; prospective study; return to work; sick leave; sickness absence; single-item question; symptom; woman; women; work ability index

This article in PubMed: www.ncbi.nlm.nih.gov/pubmed/20372766

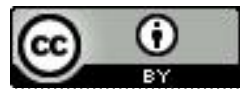




\title{
The work ability index and single-item question: associations with sick leave, symptoms, and health - a prospective study of women on long-term sick leave
} by Linda AhIstrom, MSc, ${ }^{1}$ Anna Grimby-Ekman, PhLic, ${ }^{1}$ Mats Hagberg, MD, ${ }^{1}$ Lotta Dellve, PhD ${ }^{1}$

\begin{abstract}
Ahlstrom L, Grimby-Ekman A, Hagberg M, Dellve L. The work ability index and single-item question: associations with sick leave, symptoms, and health - a prospective study of women on long-term sick leave. Scand J Work Environ Health. 2010;36(5):404-412.
\end{abstract}

\begin{abstract}
Objectives This study investigated the association between the work ability index (WAI) and the single-item question on work ability among women working in human service organizations (HSO) currently on long-term sick leave. It also examined the association between the WAI and the single-item question in relation to sick leave, symptoms, and health. Predictive values of the WAI, the changed WAI, the single-item question, and the changed single-item question were investigated for degree of sick leave, symptoms, and health.

Methods This cohort study comprised 324 HSO female workers on long-term ( $>60$ days) sick leave, with follow-ups at 6 and 12 months. Participants responded to questionnaires. Data on work ability, sick leave, health, and symptoms were analyzed with regard to associations and predictability. Spearman correlation and mixedmodel analysis were performed for repeated measurements over time.

Results The study showed a very strong association between the WAI and the single-item question among all participants. Both the WAI and the single-item question showed similar patterns of associations with sick leave, health, and symptoms. The predictive value for the degree of sick leave and health-related quality of life (HRQoL) was strong for both the WAI and the single-item question, and slightly less strong for vitality, neck pain, both self-rated general and mental health, and behavioral and current stress.
\end{abstract}

Conclusion This study suggests that the single-item question on work ability could be used as a simple indicator for assessing the status and progress of work ability among women on long-term sick leave.

Key terms cohort study; female; longitudinal data; return to work; sickness absence.

Long-term sick leave has become a main public health problem (1). There is a high prevalence of employees on long-term sick leave in Sweden (2), with the highest prevalence seen among women working in human service organizations (HSO) (3-6). HSO employees encompass, for example, workers in schools, preschools, home care service, and nursing or disabled-care homes who are in direct contact with clients or responsible for cleaning, cooking, or administration. Compared with social insurance systems in other countries, the possible length of sick leave has, until recently, been almost unlimited in Sweden. Partial sick leave is promoted in Sweden and is assumed to have positive effects on the return to full-time work (7). There is now increased focus on return to work among individuals on long-term sick leave.

The main challenge among persons on long-term sick leave is in assessing work ability and how it influences the return-to-work process. The concept of work ability is broad, comprising the physical, psychological, and social capability $(8-10)$ of a worker to perform and interact within their work, and the individual's specific work demands, health conditions, and mental resources $(11,12)$. In occupational and primary healthcare, work ability is a multidimensional condition and complex to assess among employees on long-term sick leave.

The work ability index (WAI) is an instrument designed for occupational health services and is used today in clinical practice as well as for research purposes worldwide to assess work ability $(8,13)$. One of the main criticisms raised against the WAI is that it contains many disparate questions more or less indirectly measuring work ability (eg, relating to diagnosis of chronic conditions and sick leave). This may have implications when the WAI is used among employees already on long-term

1 Occupational and Environmental Medicine, Sahlgrenska Academy, University of Gothenburg, Gothenburg, Sweden.

Correspondence to: Linda Ahlstrom, Occupational and Environmental Medicine, Sahlgrenska Academy, University of Gothenburg, Medicinaregatan 16, Po 414, S-405 30 Gothenburg, Sweden. [E-mail: linda.ahlstrom@amm.gu.se] 
sick leave; also, it may give too much weight to diagnoses not necessarily related to work ability. Due to the theoretical complexity and practical issues, the single-item question on work ability has often replaced the WAI in clinical work and research $(9,14)$. Using single-item questions can be beneficial in terms of simplicity, cost, and ease of interpretation (15). However, the agreement between the single-item question on work ability and the WAI has not been fully investigated. Radkiewicz \& Widerszal-Bazyl (16) and Torgén (17), in their cross-sectional studies of nurses in Europe and among the Swedish population, respectively, showed relatively strong agreement between the WAI and the single-item question on work ability. De Zwart et al (18), in their study of test-retest reliability among elderly construction workers, support the usefulness of the WAI in occupational healthcare and research. However, the authors argue that there is a need for more documented reliability testing of the WAI instrument.

Validity aspects of the WAI with regard to gender, type of diagnosis $(8,19)$, degree of sick leave, symptoms, and health may differ. It has been found that women often achieve lower WAI scores than men (17, 20). Occupational healthcare providers require effective usable, valid, and reliable instruments to assess work ability status and progress, as well as factors predicting return to work $(19,21,22)$.

The aims of this study were to investigate the association between the WAI and the single-item question on work ability as well as the association between the WAI and the single-item question in relation to sick leave, symptoms, and health among HSO workers on long-term sick leave.

The following research questions were investigated: (i) Is there an association between the WAI and the single-item question? Is there an association between changes in the WAI and changes in the single-item question? (ii) Is there an association between the WAI and the single-item question with regard to sick leave, symptoms, and health variables in repeated measurements? and (iii) In longitudinal analysis, what are the predictive values of the WAI and the single-item question on work ability for the degree of sick leave, symptoms, and health?

\section{Methods}

\section{Study design and setting}

Approved by the Ethics Committee of Gothenburg University, this cohort study reports baseline and prospective results, with follow-up at 6 and 12 months.

At the time of this study, the Swedish social security system paid sick leave of $>2$ weeks, including periods of almost unlimited length (7). A physician decided on the degree of sick leave, which usually changed in increments of $25 \%$. If sick leave was required, the primary recommendation was usually partial sick leave (25-100\% of full-time work).

\section{Sampling process and study sample}

Starting in August 2005, we studied a cohort of 35-65year-old female HSO workers on long-term sick leave and employed by one of Sweden's three metropolitan cities. Half of the councils within the region, representing various socioeconomic statuses, were invited to take part in the study during the first year. Employees on long-term sick leave working for these councils were invited to participate in the study if they met the inclusion criteria of being (i) a woman and (ii) on current long-term ( $>60$ days') sick leave of $\geq 50 \%$ work time. All employees meeting these criteria $(\mathrm{N}=633)$ were sent information about the study. After having answered the baseline questionnaire, participants were mailed a second and third questionnaire at 6 and 12 months, respectively. For all questionnaires, one reminder letter was sent. About $51 \%(\mathrm{~N}=324)$ participated in the first wave, while 233 $(233 / 324=72 \%)$ participated in the second wave, and $194(194 / 324=60 \%)$ participated in the third wave. The response from the participants who decided to participate in the second and/or third wave was $76 \%(\mathrm{~N}=246)$ of those who participated in the first wave. Altogether, there were 751 questionnaires to analyze. Throughout the study, the questionnaires consisted of the same questions with regard to dependent and independent variables.

\section{Work ability}

The WAI instrument consists of seven dimensions, namely: (i) current work ability compared with the lifetime best; (ii) work ability in relation to the demands of the job; (iii) number of current diseases diagnosed by a physician; (iv) estimated work impairment due to disease; (v) sick leave during the past year (12 months); (vi) own prognosis of work ability two years from now; and (vii) mental resources (worker's life in general, both at work and during leisure time) (8). These dimensions are derived as the sum of ten items. Possible scores range from 7-49 and are classified as follows: 7-27 (poor), 28-36 (moderate), 37-43 (good), and 44-49 (excellent) (13, 23, 24).

In this study, the single-item question concerned the WAI item "current work ability compared with the lifetime best", with a possible score of 0 ("completely unable to work") to 10 ("work ability at its best") $(8,14)$.

The changed WAI/changed single-item question was the difference between one point in time and the previous point in time (ie, the difference between the 6-month score and baseline or the difference between 
the 12-month and the 6-month value). Hence, changes represent a 6-month time period.

\section{Sick leave}

The degree of sick leave ranged from $0-100 \%$. The categorization for this variable was done based on the response to one item in the questionnaire, namely, "What is your current work status?" [The possible responses were: (i) on full-time/part-time sick leave; (ii) on full-time/part-time temporary disability pension; and (iii) working full-time/part-time. The response specified the percentage of each status and the starting date of the current status]. In two-thirds of the cases, the self-reported data was compared with employers' register-based data or medical records, to make the data as accurate as possible (25).

\section{Symptoms and health}

Pain in the neck was measured using items from an instrument developed by Von Korff et al (26), a numeric pain scale of $0-10$ ranging from 0 ("no pain") to 10 ("worst pain"), and measuring "present pain", "worst imaginable pain last month", and "average pain last month". The calculation is the average of these three measures multiplied by 10 and expressed as a $0-100$ score (27).

Current stress was measured with a single-item question (including a description of what is meant by "stress") taken from the Nordic Questionnaire for Psychological and Social Factors at Work (QPS Nordic), which has been validated in previous studies (28). Current stress was measured on a scale ranging from 0 ("none at all") to 4 ("very much"). A score of 3-4, indicating the highest stress levels, was used to indicate current stress in this study.

Self-rated general health (5 items), self-rated mental health (5 items), behavioral stress (5 items), and vitality (4 items) were measured with the Copenhagen Psychosocial Questionnaire (29). Each response scale was recalculated to $0-100$ points. For health-related quality of life (HRQoL), we used the EuroQol thermometer/ EQ-VAS, a global question which is part of the EuroQol-EQ-5D and uses a visual analog scale of 0-100 of the general HRQoL status (30-32).

\section{Analysis}

Descriptive statistics of the WAI, the single-item question on work ability, and variables for the factors studied in the cohort are presented in percent, means, and standard deviation (SD). Spearman correlation was used to analyze the association between the two variables - the WAI and the single item variable - as well as for the association between WAI and single-item results regarding sick leave, symptoms, and health. According to Altman (33), the correlation was evaluated as very strong $(\mathrm{r}=0.81$ $1.00)$, strong $(\mathrm{r}=0.61-0.80)$, moderate $(\mathrm{r}=0.41-0.60)$, fair $(\mathrm{r}=0.21-0.40)$, or weak $(\mathrm{r} \leq 0.20)$. To describe the baseline relation between WAI and single-item outcomes, a scatter plot of baseline variables was completed. A scatter plot was also completed for the relation between changed WAI and the changed single-item outcomes. We performed repeated measurements over time and multivariate models on the associations of sick leave, symptoms, and health with WAI and single-item outcomes.

Mixed models were used for a longitudinal analysis of the repeated measurements of prospective degree of sick leave, HRQoL, vitality, and neck pain, as well as self-rated general and mental health, behavioral and current stress. These analyses were performed with four different models where the explanatory variables were the WAI and changed WAI, and the single-item question and changed single-item question outcomes. In models A and $\mathrm{B}$, the values for the changed WAI and changed singleitem question were based on the difference between the current outcome and that measured 6 months previously. In models $\mathrm{C}$ and $\mathrm{D}$, the values for the changed WAI and changed single-item question were based on the difference between the current outcome and that measured 12 months previously. A stepwise-forward-selection approach was used with a P-value of $\leq 0.10$ for the initial selection for variable inclusion in the final model. We checked for multicollinearity. If the correlation was $r>0.7$, we excluded one of the variables. Multicollinearity was found between behavioral stress and self-rated mental health; consequently, the latter was excluded. Results from the regression analysis are presented with parameter estimates, $95 \%$ confidence intervals $(95 \% \mathrm{CI})$, and between-person/within-person variance. In the analyses mentioned, WAI and single-item results were used as if they were continuous and not ordinal variables. Therefore, these results ought to be interpreted with caution and without emphasis on the size of parameter estimates, but rather as indications of associations. All analyses were performed using JMP $\AA$, version 7 (SAS Institute Inc, Cary, NC, USA), except for the mixed models Proc Mix analysis, which was performed using SAS, version 9.1 (SAS Institute Cary, NC, USA).

\section{Results}

\section{Characteristics of the study population}

About one-third (28\%) of the participants were 35-44 years of age, $43 \%$ were $45-54$ years old, and $29 \%$ were aged between $55-65$ years. At baseline, most (72\%) of the participants were on full-time sick leave. Table 1 shows 
baseline, 6-month, and 12-month follow-up characteristics of the study population. At the start of the study, the participants had been on long-term sick leave for between just over 60 days and 14 years, with a mean of 458 days.

Altogether $67 \%$ of the participants scored within the WAI category "poor", while $26 \%$ had a "moderate" and 7\% a "good"-to-"excellent" WAI score. Among individuals on $25-100 \%$ sick leave, most scored "poor" (71-78\%) or "moderate" (17-29\%) work ability. A total of $5 \%$ of the participants on $85-100 \%$ sick leave scored within the WAI category "good". For the single-item question, the scores were: $0(20 \%), 1(6 \%), 2(9 \%), 3-8$ (61\%), and 9-10 (4\%). Independent of the degree of sick leave, most participants had a single-item question work ability score of 3-8.

\section{Association with work ability}

The Spearman correlation between WAI and single-item outcomes on work ability was very strong among all participants at baseline $(\mathrm{r}=0.87)$. Likewise, the Spearman correlation was strong between the changed WAI and changed single-item question on work ability $(\mathrm{r}=0.71)$.

The scatter plot of WAI and single-item data reveals a linear relationship between the two variables (figure 1), even though each single item corresponds to a wide range of WAI scores. A single-item score of $\leq 2$ corresponds to the WAI category of "poor", while singleitem scores of 3-6 correspond to the WAI categories of "poor" and "moderate". Of participants with a score of 7 or 8 for the single-item question, $88 \%$ were within a "moderate" or "good" WAI category. A single-item score of 9 or 10 could be categorized as "good" or "excellent"
WAI. Furthermore, the scatter plot of changed WAI and changed single-item outcomes (figure 2) shows a linear relationship.

Both the WAI and single-item outcomes were "moderate" for the degree of sick leave ( $\mathrm{r}=0.43$ and $\mathrm{r}=0.47$ ) and health $(\mathrm{r}=0.45-0.66)$. The correlation varied for different symptoms ( $\mathrm{r}=0.15-0.45)$. The WAI association with regard to self-reported symptoms and health was slightly stronger than the single-item association, with the exception of HRQoL.

In the analysis of repeated measurements over time, more explanatory variables were statistically significant for the WAI than the single-item question (table 2). The parameter estimates were slightly higher for the WAI than the single-item results. In case of a change in the explanatory variables, the effect would not be large for either WAI or single-item results. The variables included in the model explain $72 \%$ [(59.4-16.4)/59.4] and $93 \%$ [(16.4-1.1)/16.4] of the between-person variance for the WAI and the single-item questions, respectively.

With the WAI as the dependent variable and the single-item question as the independent variable, the intercept and slope were at 13.6 and 2.7, respectively, which is close to the baseline values (figure 1). Singleitem outcomes explain $84 \%$ [(59.4-9.6)/59.4] of the between-person variance for the WAI, and 66\% [(30.110.4)/30.1] of the within-person variance.

\section{Prospective association}

The WAI and changed WAI results, as well as singleitem and changed single-item results, predicted the future degree of sick leave, HRQoL, vitality, neck pain,

Table 1. Descriptive characteristics of women working in human service organizations currently on long-term sick leave (at baseline, 6 months, and 12 months). Data are given as means and standard deviation (SD).

\begin{tabular}{|c|c|c|c|c|c|c|c|c|c|c|}
\hline & \multirow[t]{2}{*}{ Scale $^{\text {a }}$} & \multicolumn{3}{|c|}{ Baseline } & \multicolumn{3}{|c|}{6 months } & \multicolumn{3}{|c|}{12 months } \\
\hline & & $\mathrm{N}^{\mathrm{b}}$ & Mean & SD & $\mathrm{N}^{\mathrm{b}}$ & Mean & SD & $\mathrm{N}^{\mathrm{b}}$ & Mean & SD \\
\hline \multicolumn{11}{|l|}{ Sick leave } \\
\hline Degree of sick leave & $0-100$ & 308 & 79 & 35 & 227 & 53 & 37 & 177 & 46 & 39 \\
\hline \multicolumn{11}{|l|}{ Symptom } \\
\hline Neck pain & $0-100$ & 314 & 36 & 30 & 212 & 34 & 30 & 186 & 36 & 29 \\
\hline Current stress & $0-4$ & 319 & 2.2 & 1.3 & 218 & 2.0 & 1.2 & 191 & 2.1 & 1.3 \\
\hline Behavioral stress & $0-100$ & 317 & 36 & 28 & 218 & 31 & 26 & 189 & 29 & 25 \\
\hline \multicolumn{11}{|l|}{ Health } \\
\hline Self-rated general health & $0-100$ & 317 & 58 & 23 & 218 & 60 & 24 & 182 & 59 & 24 \\
\hline Self-rated mental health & $0-100$ & 319 & 54 & 23 & 219 & 60 & 21 & 189 & 60 & 23 \\
\hline Vitality & $0-100$ & 319 & 40 & 21 & 219 & 44 & 20 & 189 & 44 & 23 \\
\hline Health-related quality of life & $0-100$ & 273 & 49 & 22 & 213 & 57 & 21 & 190 & 58 & 23 \\
\hline \multicolumn{11}{|l|}{ Work ability } \\
\hline Work ability index (WAI) & $7-49$ & 290 & 24 & 9 & 184 & 27 & 10 & 169 & 28 & 10 \\
\hline Single item question & $0-10$ & 315 & 4 & 3 & 198 & 5 & 3 & 184 & 5 & 3 \\
\hline
\end{tabular}

a Except for the degree of sick leave, which is scored in percent, the scales show possible range in points.

${ }^{\mathrm{b}}$ Numbers vary due to missing answers in the questionnaires. 


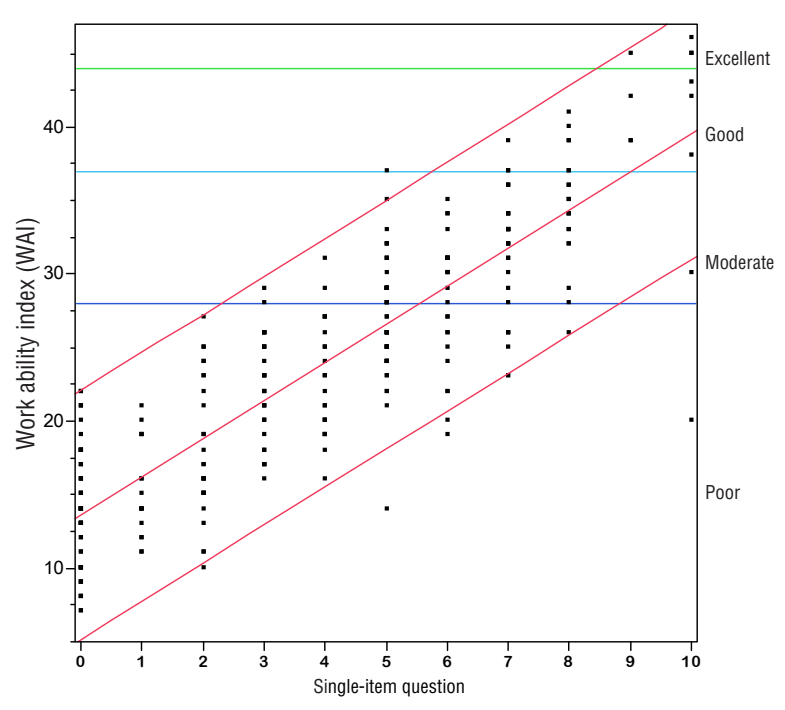

Figure 1. Scatter plot of the work ability index (WAI) and single item on work ability at baseline. The figure shows $95 \%$ confidence intervals and the WAI categories "excellent", "good", "moderate", and "poor".

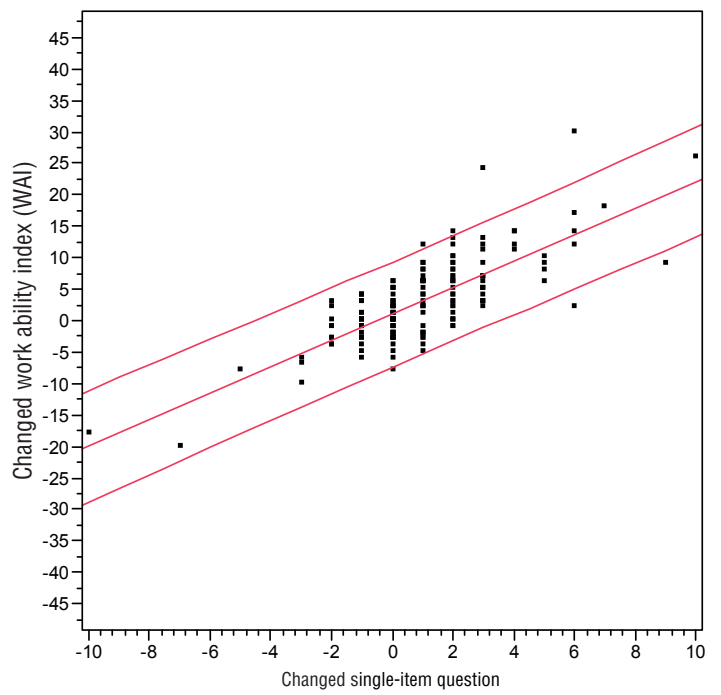

Figure 2. Scatter plot of the values for changed work ability index (WAI) and changed single item on work ability (6 months-baseline). The figure shows $95 \%$ confidence intervals.

Table 2. Repeated measurements over time. Multivariate models to show the associations between the degree of sick leave, health-related quality of life, self-rated general health, vitality, behavioral stress, neck pain, and current stress using the work ability index (WAI) and the single-item question on work ability among 324 women working in human service organizations. [ $95 \% \mathrm{Cl}=95 \%$ confidence interval; $\mathrm{b}=$ parameter estimate; $\mathrm{NI}=$ not included]

\begin{tabular}{|c|c|c|c|c|c|c|}
\hline & \multicolumn{3}{|c|}{ WAI measurements $(\mathrm{N}=541)$} & \multicolumn{3}{|c|}{ Single-item question measurements $(\mathrm{N}=603)$} \\
\hline & Scale & $b$ & $95 \% \mathrm{Cl}$ & Scale & $b$ & $95 \% \mathrm{Cl}$ \\
\hline Intercept & & 20.73 & $18.03-23.42$ & & 2.35 & $1.57-3.14$ \\
\hline Degree of sick leave & $0-100$ & -0.09 & $-0.10--0.08$ & $0-100$ & -0.03 & $-0.034--0.026$ \\
\hline Health-related quality of life & $0-100$ & 0.10 & $0.07-0.12$ & $0-100$ & 0.04 & $0.03-0.05$ \\
\hline Self-rated general health & $0-100$ & 0.05 & $0.03-0.08$ & $\mathrm{NI}$ & $\mathrm{NI}$ & $\mathrm{NI}$ \\
\hline Vitality & $0-100$ & 0.09 & $0.06-0.12$ & $0-100$ & 0.03 & $0.026-0.044$ \\
\hline Behavioral stress & $0-100$ & -0.02 & $-0.04-0.002$ & $\mathrm{NI}$ & $\mathrm{NI}$ & $\mathrm{NI}$ \\
\hline Neck pain & $0-100$ & -0.03 & $-0.05--0.02$ & $\mathrm{NI}$ & $\mathrm{NI}$ & $\mathrm{NI}$ \\
\hline Current stress & $\mathrm{NI}$ & $\mathrm{NI}$ & $\mathrm{NI}$ & $0-4$ & 0.13 & $-0.01-0.27$ \\
\hline Within-person variance & & 11.41 & & & 2.05 & \\
\hline Between-person variance & & 16.41 & & & 1.11 & \\
\hline
\end{tabular}

self-rated general and mental health, and behavioral and current stress (tables 3 and 4). For models A and B (6 months), WAI variables explained 84\% [(255.941.6)/255.9] of the between-person variance and $14 \%$ [(208.0-178.5)/208.0] of the within-person variance in HRQoL, and $63 \%[(1,075.4-401.1) / 1,075.4]$ of the between-person variance and 34\% [(384.6-254.2)/384.6] of the within-person variance in the degree of sick leave. Single-item variables explained $72 \%$ [(277.1$78.1) / 277.1]$ of the between-person variance and $6 \%$ [(189.1-177.3)/189.1] of the within-person variance for HRQoL, and $67 \%$ [(1,044.1-345.9)/1,044.1] of the between-person variance and 31\% [(395.7-273.1)/395.7] of the within-person variance for the degree of sick leave. Overall, WAI and single-item variables explained
$5-37 \%$ of the between-person variance and $4-31 \%$ of the within-person variance for vitality, self-rated general health, current stress, behavioral stress, self-rated mental health, and neck pain. Most often, WAI and changed WAI scores explained more of the betweenperson variance compared with single-item and changed single-item scores. The same pattern was shown for within-person-variance.

For models $\mathrm{C}$ and D (12 months), WAI and singleitem scores explained 61\% [(1581.5-611.4)/1581.5] and $52 \%$ [(1331.9-644.6)/1331.9], respectively, of the between-person variance in the degree of sick leave. Also, WAI variables and single-item variables explained $13-36 \%$ of the between-individual variance for vitality, behavioral stress, mental health, neck pain, and current 
Table 3. Linear regression with repeated measurements (mixed model) analyzing the predictive value of the degree of sick leave, healthrelated quality of life, vitality, and neck pain (at 6 months and 12 months) among women working in human service organizations. In models $\mathrm{A}$ and $\mathrm{C}$, work ability index (WAI) and changed WAI results are explanatory factors. In model $\mathrm{B}$ and model $\mathrm{D}$, single-item and changed single-item results are explanatory factors. [95\% $\mathrm{Cl}=95 \%$ confidence interval; $b=$ parameter estimate; NI=not included]

\begin{tabular}{|c|c|c|c|c|c|c|c|c|c|c|c|c|}
\hline & \multicolumn{3}{|c|}{ Degree of sick leave } & \multicolumn{3}{|c|}{ Health-related quality of life } & \multicolumn{3}{|c|}{ Vitality } & \multicolumn{3}{|c|}{ Neck pain } \\
\hline & N & b & $95 \% \mathrm{Cl}$ & N & b & $95 \% \mathrm{Cl}$ & N & $b$ & $95 \% \mathrm{Cl}$ & N & b & $95 \% \mathrm{Cl}$ \\
\hline \multicolumn{13}{|l|}{ 6-month follow-up } \\
\hline Model Aa & 285 & .. & .. & 288 & .. & .. & 293 & .. & .. & 283 & .. & .. \\
\hline Intercept & - & 132.6 & $122.30-142.95$ & - & 15.5 & $9.88-21.01$ & - & 10.8 & $4.14-17.50$ & - & 61.8 & $50.97-72.56$ \\
\hline WAI & - & -3.1 & $-3.45--2.70$ & - & 1.6 & $1.37-1.77$ & - & 1.2 & $0.92-1.40$ & - & -1.0 & $-1.38--0.60$ \\
\hline Changed WAI & - & -2.4 & $-2.83--2.00$ & - & 1.5 & $1.20-1.75$ & - & 2.4 & $1.46-3.26$ & - & -1.2 & $-1.62--0.82$ \\
\hline WAI $\times$ changed WAI & - & $\mathrm{NI}$ & $\mathrm{NI}$ & - & $\mathrm{NI}$ & $\mathrm{NI}$ & - & -0.03 & $-0.04-0.00$ & - & $\mathrm{NI}$ & $\mathrm{NI}$ \\
\hline Between-person variance & - & 401.1 & .. & - & 41.6 &.. & - & 141.2 & .. & - & 547.0 & .. \\
\hline Within-person variance & - & 254.2 & .. & - & 178.5 & .. & - & 141.9 & .. & - & 190.3 & .. \\
\hline Model Ba & 327 & .. & .. & 329 & .. & .. & 336 & .. & .. & 326 & .. & .. \\
\hline Intercept & - & 101.5 & $95.36-107.72$ & - & 32.1 & $28.25-35.96$ & - & 25.6 & $21.13-30.11$ & - & 43.6 & $36.40-50.78$ \\
\hline Single item & - & -10.6 & $-11.75--9.48$ & - & 5.1 & $4.37-5.79$ & - & 3.7 & $2.83-4.48$ & - & -1.9 & $-3.17--0.66$ \\
\hline Changed single item & - & -7.1 & $-8.20--5.90$ & - & 4.7 & $3.85-5.51$ & - & 3.4 & $2.55-4.31$ & - & -0.2 & $-2.10-1.65$ \\
\hline $\begin{array}{l}\text { Single item } \times \text { changed } \\
\text { single item }\end{array}$ & - & $\mathrm{NI}$ & $\mathrm{NI}$ & - & $\mathrm{NI}$ & $\mathrm{NI}$ & - & $\mathrm{NI}$ & $\mathrm{NI}$ & - & -0.3 & $-0.64--0.03$ \\
\hline Between-person variance & - & 345.9 & .. & - & 78.1 &.. & - & 157.4 & .. & - & 636.1 & .. \\
\hline Within-person variance & - & 273.2 & .. & - & 177.3 &.$\cdot$ & - & 184.7 & .. & - & 186.3 & .. \\
\hline \multicolumn{13}{|l|}{ 12-month follow-up } \\
\hline Model $\mathrm{C}^{\mathrm{a}}$ & 146 & .. & .. & 155 & .. & .. & 156 & .. & .. & 151 & .. & .. \\
\hline Intercept & - & 127.5 & $114.14-140.93$ & - & 13.8 & $5.21-22.42$ & - & 14.7 & $4.90-24.47$ & - & 65.4 & $50.87-79.88$ \\
\hline WAI & - & -2.9 & $-3.38--2.37$ & - & 1.6 & $1.25-1.90$ & - & 1.0 & $0.62-1.35$ & - & -1.0 & $-1.58--0.47$ \\
\hline Changed WAI & - & -3.0 & $-3.53--2.55$ & - & 1.2 & $1.36-1.97$ & - & 1.5 & $1.14-1.82$ & - & -1.2 & $-1.70--0.66$ \\
\hline Between-person variance & e - & 611.4 & .. & - & 260.3 &.. & - & 336.6 &.. & - & 711.7 & .. \\
\hline Model Da & 168 & .. & .. & 179 & .. &.$\cdot$ & 181 & .. & .. & 175 & .. & .. \\
\hline Intercept & - & 94.6 & $85.93-103.27$ & - & 26.6 & $21.40-31.74$ & - & 20.7 & $14.54-26.76$ & - & 51.0 & $42.21-59.70$ \\
\hline Single item & - & -10.1 & $-11.67--8.52$ & - & 6.0 & $5.05-6.95$ & - & 4.1 & $3.01-5.25$ & - & -3.0 & $-4.64--1.30$ \\
\hline Changed single item & - & -7.5 & $-9.83--5.12$ & - & 6.7 & $5.45-7.99$ & - & 6.2 & $4.72-7.73$ & - & -2.8 & $-4.37--1.26$ \\
\hline $\begin{array}{l}\text { Single item } \times \text { changed } \\
\text { single item }\end{array}$ & - & -0.6 & $-1.05--0.14$ & - & -0.2 & $-0.47--0.01$ & - & -0.3 & $-0.61--0.62$ & - & $\mathrm{NI}$ & (1) 2 - \\
\hline Between-person variance & - & 644.6 & .. & - & 250.8 & .. & - & 350.8 & .. & - & 772.9 & .. \\
\hline
\end{tabular}

a Numbers vary due to missing answers in the questionnaires.

stress. With regard to the dependent variables, the WAI variables explained the between-individual variance slightly better than the single-item question variables.

Both models A and B explained more of the betweenperson variance for the dependent variables degree of sick leave, HRQoL, and vitality, compared with models $\mathrm{C}$ and $\mathrm{D}$. The reverse applied to the dependent variables of self-rated mental health, and both behavioral and current stress.

\section{Discussion}

The results of this study demonstrate that, in occupational and primary healthcare, a single-item question on work ability may be a good alternative to the WAI for assessing the status and progress of work ability among women on long-term sick leave.

The single-item question on work ability had a strong correlation with the WAI among all participants.
The results cohere with data from a general working population, showing that WAI and single-item results for women with lower work ability scores had a rank correlation of 0.7 , which was higher than among men and those with higher work ability scores (17).

Several cross-sectional studies have shown a relation with health conditions. For example, the WAI has been found to be related to mental and physical wellbeing, general health perception, emotional exhaustion, and disability in ten European countries (16). A recent review of factors associated with the WAI showed the multifactorial nature of work ability measured with the WAI. Physical conditions, demands at work, individual characteristics, and lifestyle were most strongly associated with the index (34). The results of our study showed similar patterns of relations to sick leave, symptoms, and health for both the WAI and the single-item question. The degree of sick leave and HRQoL had the strongest relation. Furthermore, in the multivariate models, the explained variance was higher for the WAI than for the single-item question in the stratified models. 
Table 4. Linear regression with repeated measurements (mixed model) analyzing the predictive value of self-rated general and mental health and behavioral and current stress. In models $\mathrm{A}$ and $\mathrm{C}$, work ability index (WAI) and changed WAI results are explanatory factors. In models $B$ and $D$, single-item and changed single-item results are explanatory factors, among women working in human service organizations. [ $95 \% \mathrm{Cl}=95 \%$ confidence interval; $b=$ parameter estimate; $\mathrm{Nl}=$ not included]

\begin{tabular}{|c|c|c|c|c|c|c|c|c|c|c|c|c|}
\hline & \multicolumn{3}{|c|}{ Self-rated general health } & \multicolumn{3}{|c|}{ Self-rated mental health } & \multicolumn{3}{|c|}{ Behavioral stress } & \multicolumn{3}{|c|}{ Current stress } \\
\hline & N & b & $95 \% \mathrm{Cl}$ & $\mathrm{N}$ & b & $95 \% \mathrm{Cl}$ & $\mathrm{N}$ & $\mathrm{b}$ & $95 \% \mathrm{Cl}$ & $\mathrm{N}$ & b & $95 \% \mathrm{Cl}$ \\
\hline \multicolumn{13}{|l|}{ 6-month follow-up } \\
\hline Model Aa & 289 & .. & .. & 293 & .. & .. & 292 & .. & .. & 291 & .. & .. \\
\hline Intercept & - & 27.5 & $19.01-36.02$ & - & 30.6 & $22.94-38.17$ & - & 62.4 & $53.39-71.41$ & - & 3.2 & $2.78-3.69$ \\
\hline WAI & - & 1.2 & $0.07-1.48$ & - & 1.0 & $0.75-1.30$ & - & -1.1 & $-1.45--0.80$ & - & -0.04 & $-0.06--0.03$ \\
\hline Changed WAI & - & 1.3 & $0.93-1.60$ & - & 1.3 & $0.97-1.55$ & - & -1.3 & $-1.65--0.97$ & - & -0.06 & $-0.08--0.04$ \\
\hline Between-person variance & - & 302.4 &.. & - & 259.5 & .. & - & 366.3 & .. & - & 0.78 & .. \\
\hline Within-person variance & - & 152.9 & .. & - & 113.4 & .. & - & 154.5 & .. & - & 0.53 & .. \\
\hline Model $\mathrm{B}^{\mathrm{a}}$ & 330 & .. & .. & 336 & .. & .. & 335 & .. & .. & 334 & .. & .. \\
\hline Intercept & - & 45.0 & $39.45-50.46$ & - & 42.6 & $37.83-47.43$ & - & 48.7 & $43.06-54.40$ & - & 2.7 & $2.38-2.96$ \\
\hline Single item & - & 3.0 & $1.98-3.97$ & - & 3.3 & $2.45-4.20$ & - & -3.6 & $-4.61--2.56$ & - & -0.1 & $-0.18--0.07$ \\
\hline Changed single item & - & 2.8 & $1.84-3.80$ & - & 3.3 & $2.45-4.12$ & - & -3.1 & $-4.12--2.17$ & - & -0.1 & $-0.19--0.09$ \\
\hline Between-person variance & - & 349.5 & .. & - & 258.2 & .. & - & 361.3 & .. & - & 0.86 & .. \\
\hline Within-person variance & - & 151.6 & .. & - & 127.2 & .. & - & 172.3 & .. & - & 0.54 & .. \\
\hline \multicolumn{13}{|l|}{ 12-month follow-up } \\
\hline Model Ca & 152 & .. & .. & 156 & .. & .. & 156 & .. & .. & 155 & .. & .. \\
\hline Intercept & - & 27.8 & $16.84-38.75$ & - & 35.2 & $24.85-46.18$ & - & 56.7 & $45.11-68.32$ & - & 3.4 & $2.70-4.00$ \\
\hline WAI & - & 1.2 & $0.80-1.62$ & - & 0.8 & $0.45-1.24$ & - & -1.0 & $-1.40-0.53$ & - & -0.04 & $-0.07--0.02$ \\
\hline Changed WAI & - & 0.8 & $0.44-1.22$ & - & 0.3 & $-0.84-1.48$ & - & -1.3 & $-1.73--0.92$ & - & -0.06 & $-0.08--0.04$ \\
\hline WAI $\times$ changed WAI & - & $\mathrm{NI}$ & $\mathrm{NI}$ & - & 0.04 & $-0.01-0.08$ & - & $\mathrm{NI}$ & $\mathrm{NI}$ & - & $\mathrm{NI}$ & $\mathrm{NI}$ \\
\hline Between-person variance & - & 401.5 & .. & - & 382.3 & .. & - & 473.5 & .. & - & 1.46 & .. \\
\hline Model Da & 174 & .. & .. & 181 & .. & .. & 181 & .. & .. & 180 & .. & .. \\
\hline Intercept & - & 40.5 & $33.83-47.14$ & - & 40.4 & $34.43-46.41$ & - & 48.0 & $41.29-54.71$ & - & 2.8 & $2.44-3.12$ \\
\hline Single item & - & 3.8 & $2.49-5.04$ & - & 3.7 & $2.54-4.83$ & - & -3.7 & $-5.01--2.45$ & - & -0.1 & $-0.22--0.07$ \\
\hline Changed single item & - & 3.3 & $2.13-4.55$ & - & 4.4 & $3.32-5.45$ & - & -4.4 & $-5.56--3.17$ & - & -0.2 & $-0.25--0.11$ \\
\hline Between-person variance & - & 434.8 & .. & - & 372.7 & .. & - & 467.7 & .. & - & 1.48 & .. \\
\hline
\end{tabular}

${ }^{a}$ Numbers vary due to missing answers in the questionnaires.

Despite numerous studies of the WAI, few studies have investigated its predictive value for future sick leave (35). In our study, both the WAI and the singleitem question strongly predicted the future degree of sick leave among women on current long-term sick leave. In two previous studies, the WAI was shown to predict future sick leave among those with lower work ability scores $(35,36)$. In one of these, the WAI predicted future long-term sick leave ( $>9$ days) among young workers scoring low work ability (36). In the other study, the index predicted long-term sick leave ( $>12$ weeks) among male construction workers with a less-than-excellent work ability initially (35). Prediction of sick leave, especially long-term sick leave, is multidimensional. This study agrees with previous studies reporting that the WAI is better for predicting future scores among those with low scores, arguing for the usefulness of the single-item question. However, as Ilmarinen recently pointed out, there is a need for more longitudinal studies on work ability $(8,13)$.

In our study, the WAI and changed WAI as well as the single-item and changed single-item question predicted the future degree of sick leave and HRQoL in particular, but also vitality, self-rated general and mental health, stress, and pain. There is research stating that it is difficult to change the pattern of work ability. It either declines or improves (8), and this can make it difficult for workers already scoring low to change their work ability pattern. In agreement with this research, in our study we can see the linearity effect of changed work ability. There were small steps of change of WAI results, especially between waves two and three of the study, which agrees with results reported by Feldt et al (37). In their study of Finnish managers, five patterns of development trajectories were identified and investigated. Younger age, high job control, higher position (ie, managerial position), supportive organizational work climate, and less physical work were predictors for improved work ability, while aging and low position at work were a risk for declined WAI (37).

\section{Practical implementation}

The results suggest that using a single-item question on work ability in occupational and primary care may be a good alternative to using the WAI. The benefits of using single-item questions in practice are argued by authors such as Bowling, especially in situations where the patient 
is vulnerable, time is short, and cost effectiveness and easy interpretation by the professional is an issue (15). Research within cancer care suggests that occupational health services use an instrument to measure work ability. To enable the individual to return to work, a standardized tool is needed to assess work ability in practice (38). Additionally, there is a need for more longitudinal research (39). In an in-depth review, Munir et al (38) mention the use of researcher-formulated, own work ability questions, or parts of the WAI not stating concerns of validity or reliability, in order to be able to draw conclusions and make comparisons with other research. Today, work ability research already includes work with single-item questions, although this is not explicitly mentioned, for example within cancer research $(40,41)$. Both the single-item question and the WAI may help the occupational healthcare professional in their daily work with patients on long-term sick leave, in assessing present status and the patients' possible progress in the return-to-work process, keeping in mind that prediction should be used with caution and merely as an indicator. It is, however, important to consider whether occupational healthcare practitioners may lose essential information when using the single-item question.

The predictability of work ability could be used as a guide in tailoring interventions and rehab activities. However, it is important to consider individuals' limitations in functions in relation to health and the possibility to cope with work as a unit (42), as well as lifestyle and the role of the close community (8) in promoting individuals' return to work.

\section{Methodological considerations}

The study raises several methodological issues - some of them already mentioned others to be discussed here. Firstly, the slightly higher variance in WAI results could be explained by the fact that items of sick leave and health are included in the WAI. The variance could also be explained by psychometric strengths due to the number of items. One limitation is the fact that the WAI includes the single-item question. However, we believe that the alternative, to exclude the single-item question from the WAI, would be less accurate as it would not reflect the complete measurement.

Secondly, the data in this study are mostly based on questionnaire results. However, for about two-thirds of the study group, the degree and status of sick leave were controlled by register-based data and medical records, with good agreement. Furthermore, a recent study comparing self-reported data on the degree of sick leave and register information concluded that self-reported data are valuable in epidemiological studies (43).

The findings can be generalized to women on longterm sick leave working within HSO, who make up the largest group of employees in Sweden and have shown the highest prevalence of long-term sick leave.

\section{Concluding remarks}

This study suggests that the single-item question on work ability could be used as a simple indicator for assessing the status and progress of work ability among women on long-term sick leave.

\section{Acknowledgements}

The authors would like to thank statistician Andreas Jonsson for his support with the database. We are grateful to the Swedish Social and Working Life Foundation for financial support.

\section{References}

1. Alexanderson K, Norlund A. Chapter 1: aim, background, key concepts, regulations, and current statistics. In: Swedish Council on Technology Assessment in Health Care (SBU). Scand J Public Health. 2004;63 suppl:12-30.

2. Stattin M. Retirement on grounds of ill health. Occup Environ Med. 2005;62(2):135-40.

3. Dellve L, Karlberg C, Allebeck P, Herloff B, Hagberg M. Macroorganizational factors, the incidence of work disability, and work ability among the total workforce of home care workers in Sweden. Scand J Public Health. 2006;34(1):17-25.

4. Leijon M, Hensing G, Alexanderson K. Sickness absence due to musculoskeletal diagnoses: association with occupational gender segregation. Scand J Public Health. 2004;32(2):94-101.

5. Larsson TJ, Normark M, Oldertz C, Tezic K. Allvarliga arbetsskador och långvarig sjukfrånvaro [Serious occupational disorders and long term sickness absence]. AFA Försäkring; 2009.

6. Borg K, Goine H, Söderberg E, Marnetoft SU, Alexanderson $\mathrm{K}$. Comparison of seven measures of sickness absence based on data from three counties in Sweden. Work. 2006;26(4):421-8.

7. Kausto J, Miranda H, Martimo KP, Viikari-Juntura E. Partial sick leave-review of its use, effects and feasibility in the Nordic countries [review]. Scand J Work Environ Health. 2008;34(4):239-49.

8. Ilmarinen J. Work ability-a comprehensive concept for occupational health research and prevention [editorial]. Scand J Work Environ Health. 2009;35(1):1-5.

9. Sluiter J, Frings-Dresen M. Quality of life and illness perception in working and sick-listed chronic RSI patients. Int Arch Occup Environ Health. 2008;81(4):495-501.

10. Pransky G, Gatchel R, Linton SJ, Loisel P. Improving return to work research. J Occup Rehabil. 2005;15(4):453-7. 
11. Tuomi K, Ilmarinen J, Seitsamo J, Huuhtanen P, Martikainen R, Nygård CH, et al. Summary of the Finnish research project (1981-1992) to promote the health and work ability of aging workers. Scand J Work Environ Health. 1997;23 suppl $1: 66-71$.

12. Ludvigsson M, Svensson T, Alexandersson K. Begreppet arbetsförmåga - en litteraturgenomgång [The concept work ability - a literature review]. Stockcholm: Arbetslivsinstitutet; 2006. Arbete och Hälsa, p 1-19.

13. Ilmarinen J. The Work Ability Index (WAI). Occup Med. 2007;57(2):160.

14. de Croon EM, Sluiter JK, Nijssen TF, Kammeijer M, Dijkmans BAC, Lankhorst GJ, et al. Work ability of Dutch employees with rheumatoid arthritis. Scand J Rheumatol. 2005;34(4):277-83.

15. Bowling A. Just one question: if one question works, why ask several? J Epidemiol Community Health. 2005;59(5):342-5.

16. Radkiewicz P, Widerszal-Bazyl M. Psychometric properties of Work Ability Index in the light of comparative survey study. Int Congr Ser. 2005;1280:304-9.

17. Torgén M. Experiences of WAI in a random sample of the Swedish working population. Int Congr Ser. 2005;1280:328-32.

18. de Zwart BCH, Frings-Dresen MHW, van Duivenbooden JC. Test-retest reliability of the Work Ability Index questionnaire. Occup Med. 2002;52(4):177-81.

19. Slebus FG, Kuijer PP, Willems HJ, Sluiter JK, Frings-Dresen MH. Prognostic factors for work ability in sicklisted employees with chronic diseases. Occup Environ Med. 2007;64:814-9.

20. Costa G, Sartori S, Bertoldo B, Olivato D, Antonacci G, Ciuffa $\mathrm{V}$, et al. Work ability in health care workers. Int Congr Ser. 2005;1280:264-9.

21. Alexanderson K, Norlund A. Chapter 12: future need for research. In: Swedish Council on Technology Assessment in Health Care (SBU). Scand J Public Health. 2004;63 suppl:256-8.

22. Ekbladh E. Return to work, assessment of subjective psychosocial and enviromental factors [dissertation]. Linköping (Sweden): Linköping University; 2008.

23. Sjögren-Rönkä T, Ojanen MT, Leskinen EK, mustalampi ST, Mälkiä EA. Physical and psychosocial prerequisites of functioning in relation to work ability and general subjective well-being among office workers. Scand J Work Environ Health. 2002;28(3):184-90.

24. Tuomi K, Ilmarinen J, Jahkola A, Katajarinne L, Tulkki A. Work Ability Index. 2 ed. Helsinki: K-print Oy; 1998.

25. Hensing G, Alexanderson K, Allebeck P, Bjurulf P. How to measure sickness absence?: literature review and suggestion of five basic measures. Scand J Soc Med. 1998;26(2):133-44.

26. Von Korff M, Ormel J, Keefe FJ, Dworkin SF. Grading the severity of chronic pain. Pain. 1992;50(2):133-49.

27. Von Korff M, Miglioretti DL. A prognostic approach to defining chronic pain. Pain. 2005;117(3):304-13.

28. Elo AL, Leppänen A, Jahkola A. Validity of a single-item measure of stress symptoms. Scand J Work Environ Health. 2003;29(6):444-51.
29. Kristensen TS, Hannerz H, Hogh A, Borg V. The Copenhagen Psychosocial Questionnaire-a tool for the assessment and improvement of the psychosocial work environment. Scand J Work Environ Health. 2005;31(6):438-49.

30. EuroQol-a new facility for the measurement of health-related quality of life. Health Policy. 1990;16(3):199-208.

31. Brooks RG, Jendteg S, Lindgren B, Persson U, Björk S. EuroQol: health-related quality of life measurement: results of the Swedish questionnaire exercise. Health Policy. 1991;18(1):37-48.

32. Rabin R, de Charro F. EQ-SD: a measure of health status from the EuroQol Group. Ann Med. 2001;33(5):337-43.

33. Altman DG. Practical statistic for medical research. London: Chapman \& Hall; 1999.

34. van den Berg TI, Elders LA, de Zwart BC, Burdorf A. The effects of work-related and individual factors on the Work Ability Index: a systematic review. Occup Environ Med. 2009;66(4):211-20.

35. Alavinia SM, van den Berg TI, van Duivenbooden C, Elders LA, Burdorf A. Impact of work-related factors, lifestyle, and work ability on sickness absence among Dutch construction workers. Scand J Work Environ Health. 2009;35(5):325-33.

36. Kujala V, Tammelin T, Remes J, Vammavaara E, Ek E, Laitinen J. Work ability index of young employees and their sickness absence during the following year. Scand J Work Environ Health. 2006;32(1):75-84.

37. Feldt T, Hyvönen K, Mäkikangas A, Kinnunen U, Kokko K. Development trajectories of Finnish managers' work ability over a 10-year follow-up period. Scand J Work Environ Health. 2009;35(1):37-47.

38. Munir F, Yarker J, McDermott H. Employment and the common cancers: correlates of work ability during or following cancer treatment. Occup Med. 2009;59(6):381-9.

39. Taskila T, Lindbohm ML. Factors affecting cancer survivors' employment and work ability. Acta Oncol. 2007;46(4):446-51.

40. Hoving JL, Bartelds GM, Sluiter JK, Sadiraj K, Groot I, Lems WF, et al. Perceived work ability, quality of life, and fatigue in patients with rheumatoid arthritis after a 6-month course of TNF inhibitors: prospective intervention study and partial economic evaluation. Scand J Rheumatol. 2009;38(4):246-50.

41. Taskila T, Martikainen R, Hietanen P, Lindbohm ML. Comparative study of work ability between cancer survivors and their referents. Eur J Cancer. 2007;43(5):914-20.

42. Alavinia SM, de Boer AGEM, van Duivenbooden JC, FringsDresen MHW, Burdorf A. Determinants of work ability and its predictive value for disability. Occup Med. 2009;59(1):32-7.

43. Voss M, Stark S, Alfredsson L, Vingård E, Josephson M. Comparisons of self-reported and register data on sickness absence among public employees in Sweden. Occup Environ Med. 2008;65(1):61-7.

Received for publication: 4 September 2009 